\title{
Condensed-Phase Photochemistry in the Absence of Radiation Chemistry
}

Ella Mullikin, ${ }^{1}$ Pierce van Mulbregt, ${ }^{2}$ Jeniffer Perea, ${ }^{1}$ Muhammad Kasule, ${ }^{3}$ Jean Huang, ${ }^{1}$ Christina Buffo, ${ }^{1}$ Jyoti Campbell, ${ }^{1}$ Leslie Gates, ${ }^{1}$ Helen M. Cumberbatch, ${ }^{1}$ Zoe Peeler, ${ }^{1}$ Hope Schneider, ${ }^{1}$ Julia Lukens, ${ }^{1}$ Si Tong Bao, ${ }^{1}$ Rhoda Tano-Menka, ${ }^{1}$ Subha Baniya, ${ }^{1}$ Kendra Cui, ${ }^{1}$ Mayla Thompson, ${ }^{1}$ Aury Hay, ${ }^{1}$ Lily Widdup, ${ }^{1}$ Anna Caldwell-Overdier, ${ }^{1}$ Justine Huang, ${ }^{1}$ Michael C. Boyer, ${ }^{3}$ Mahesh Rajappan, ${ }^{4}$ Geraldine Echebiri, ${ }^{1}$ and Christopher R. Arumainayagam ${ }^{1 *}$

${ }^{1}$ Department of Chemistry, Wellesley College, Wellesley, MA 02481

${ }^{2}$ Dickinson College, Carlisle, PA 17013

${ }^{3}$ Department of Physics, Clark University, Worcester, MA 01610

${ }^{4}$ Center for Astrophysics, Harvard University, Cambridge, MA 02138

*Corresponding Author: Email: carumain@wellesley.edu; Telephone: 781-283-3326; FAX:

$781-283-3642$ 


\section{Abstract}

We report post-irradiation photochemistry studies of condensed ammonia using photons of energies below condensed ammonia's ionization threshold of $\sim 9 \mathrm{eV}$. Hydrazine $\left(\mathrm{N}_{2} \mathrm{H}_{4}\right)$, diazene (also known as diimide and diimine) $\left(\mathrm{N}_{2} \mathrm{H}_{2}\right)$, triazane $\left(\mathrm{N}_{3} \mathrm{H}_{5}\right)$, and one or more isomers of $\mathrm{N}_{3} \mathrm{H}_{3}$ are detected as photochemistry products during temperature-programmed desorption. Product yields increase monotonically with (1) photon fluence and (2) film thickness. In the studies reported herein, the energies of photons responsible for product formation are constrained to less than $7.4 \mathrm{eV}$. Previous post-irradiation photochemistry studies of condensed ammonia employed photons sufficiently energetic to ionize condensed ammonia and initiate radiation chemistry. Such studies typically involve ion-molecule reactions and electron-induced reactions in addition to photochemistry. Although photochemistry is cited as a dominant mechanism for the synthesis of prebiotic molecules in interstellar ices, to the best of our knowledge, ours is one of the first astrochemically-relevant studies that has found unambiguous evidence for condensed-phase chemical synthesis induced by photons in the absence of ionization.

\section{TOC GRAPHIC}

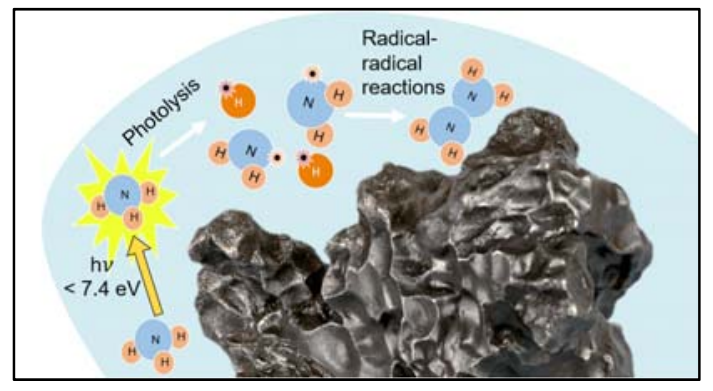

KEYWORDS astrochemistry, ammonia, interstellar medium, non-ionizing, photons, ice 


\section{Introduction}

Photochemistry is the study of the chemical processing of materials by UV and visible photons which cause excitation but lack sufficient energy to cause ionization. ${ }^{1}$ Visible, near$\mathrm{UV}$, and far-UV photons, collectively spanning the $1.8-6.2 \mathrm{eV}$ energy range, initiate only photochemistry in a typical molecule. A molecule excited by such low-energy photons may undergo (1) photolysis (bond cleavage), producing radicals; (2) photoisomerization followed by dissociation, engendering stable molecules; (3) H-abstraction, resulting in the excited molecule abstracting a hydrogen atom from a nearby molecule; or (4) photosensitization, giving rise to energy or electron transfer between the excited molecule and another species. ${ }^{2}$

None of the above photochemical processes yield secondary electrons, which play a central mediating role in radiation chemistry. Unlike photochemistry, radiation chemistry concerns the chemical processing of materials by radiation of sufficiently high energy to cause ionization. ${ }^{3}$ Phenomena unique to radiation chemistry include (1) cascades of non-thermal, lowenergy ( $\leq 20 \mathrm{eV}$ ) electrons; (2) non-uniform distributions of reaction intermediates; and (3) nonselective chemistry due to the plethora of excited states, ions, and radicals produced by ionizing radiation.

Due in part to these phenomena, radiation chemistry differs from photochemistry and may not follow photochemical laws such as the Bunsen-Roscoe law, according to which the reaction yield is directly proportional to total irradiation dose, irrespective of the time required to deliver that dose. ${ }^{4}$ In contrast, the dose-rate effect in radiation chemistry is often associated with high linear energy transfer radiation such as heavy ions which are found in galactic cosmic rays. 
Differentiating pure photochemistry from radiation chemistry requires careful consideration of ionization threshold energies, especially in studies of condensed-phase material. The threshold for producing secondary electrons is lower in the condensed phase than in the gas phase for a given molecule; for example, the photoelectric emission threshold for amorphous water ice (the main constituent of cosmic ices) is $\sim 10.2 \mathrm{eV}$, which is lower than water's gas-phase ionization energy of $12.6 \mathrm{eV} .^{5-6}$ This reduction in ionization threshold energy from gas phase to condensed phase is a general phenomenon and has been ascribed to dielectric screening of the hole produced by ionizing radiation in condensed matter. ${ }^{7}$ For ammonia, this relaxation shift reduces the ionization energy from $10.2 \mathrm{eV}$ in the gas phase to $\sim 9 \mathrm{eV}$ in the condensed phase..$^{8-9}$

Most previous "photochemistry" studies of condensed ammonia utilized photons of sufficiently high energies to cause ionization in the condensed phase and, therefore, initiate radiation chemistry. Ion-molecule (e.g., $\mathrm{NH}_{4}{ }^{+}-\mathrm{NH}_{3}$ ) reactions cannot be ruled out in such studies. Low-energy $(<10 \mathrm{eV})$ secondary electrons may also initiate chemical reactions in such "photochemistry" studies. These potential radiation chemistry contributions are especially significant for those studies utilizing hydrogen microwave-discharge lamps, which have a significant Lyman- $\alpha(10.2 \mathrm{eV})$ photon contribution. Radiolysis is likely a contributing factor in previous results of both photon-stimulated desorption and post-irradiation temperatureprogrammed desorption experiments which indicate the photon-induced production of hydrazine or diazene (diimide) or both. ${ }^{10-13}$

Only two prior studies of condensed ammonia have investigated photochemistry in the absence of radiation chemistry. ${ }^{14,15}$ Of all the possible photolysis/radiolysis products of ammonia (Chart 1), only atomic and molecular hydrogen, atomic and molecular nitrogen, 
ammonia, ammonium cation, and the imine (imidogen) $(\mathrm{NH})$ radical were reported as desorption products of $6.4 \mathrm{eV}$ photon-irradiated pure ammonia ices. ${ }^{14,15}$ Both studies utilized photon-stimulated desorption, which does not necessarily provide a complete understanding of condensed-phase photochemistry because inelastic collisions may inhibit desorption of photochemistry products. Moreover, mass spectrometer-based photon-stimulated desorption experiments may be inadequate to determine product identity because all species desorb at the same temperature, in contrast to post-irradiation temperature-programmed desorption experiments. The post-irradiation experiments described herein uniquely focus on pure photochemistry-i.e., only photons that cannot cause ionization are used.

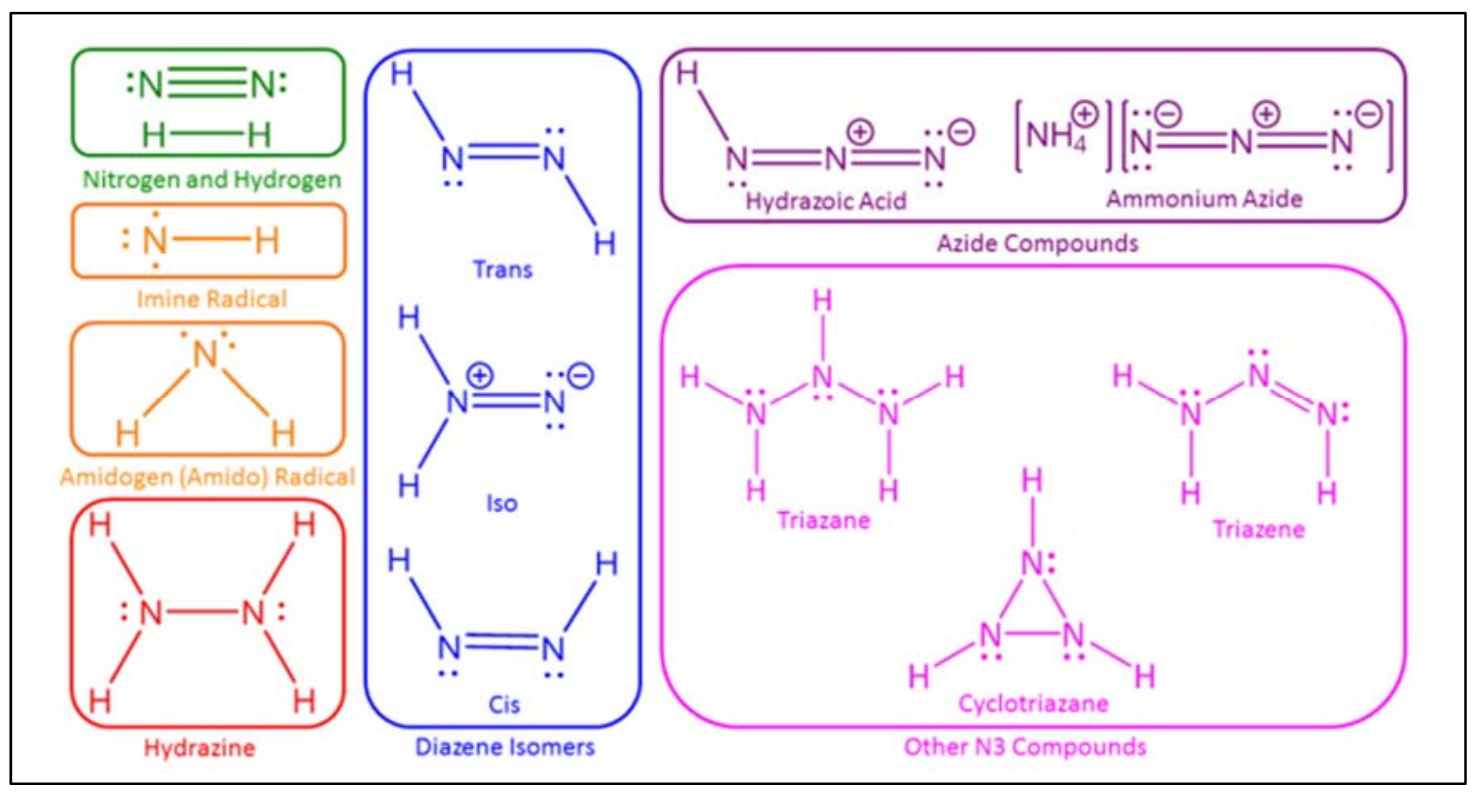

Chart 1. Lewis structures of Possible Photolysis/Radiolysis Products of Ammonia.

Studies such as this that probe condensed-phase photochemistry involving non-ionizing radiation are important in the field of astrochemistry. The energetic processing of icy dust grains in dark, dense molecular clouds (a principal locale for the interstellar synthesis of complex organic molecules) involves both non-ionizing radiation and ionizing radiation. ${ }^{16}$ The 
ice mantles of these dust grains are primarily comprised of condensed water, carbon dioxide, carbon monoxide, methanol, methane, and ammonia. ${ }^{17}$ With the possible exception of molecular nitrogen whose abundance in interstellar ices is not known, ammonia is the most abundant nitrogenous compound in such ices, with an abundance of $1-10 \%$ relative to that of water. ${ }^{18-19}$ Ammonia is thus a likely precursor to prebiotic molecules such as the amino acid glycine, which was recently detected in the coma surrounding comet $67 \mathrm{P} / \mathrm{Churyumov}$ Gerasimenko. $^{20}$

Radiation chemistry can be initiated in the interstellar medium by high-energy particulate constituents of cosmic rays ${ }^{17}$ or by high-energy photons such as vacuum-UV, extreme-UV, X-ray, and $\gamma$-ray photons. Interactions of energetic species (e.g., cosmic rays and Lyman- $\alpha$ photons) with interstellar ices also liberate cascades of low-energy $(\leq 20 \mathrm{eV})$ secondary electrons which play a central role in the chemical processing of cosmic ices. ${ }^{21}$ In dense molecular clouds, although external UV radiation is strongly extinguished, cosmic rays may penetrate and interact with gas-phase hydrogen molecules, generating internal photons with energies ranging from $6.2 \mathrm{eV}$ to $13.6 \mathrm{eV} .{ }^{16}$ While higher-energy internal photons can initiate radiation chemistry, internal photons with energy less than $\sim 10 \mathrm{eV}$ exclusively induce photochemistry in interstellar ices. By using a UV source whose photon energy is less than $7.4 \mathrm{eV}$, we report, herein, cosmic ice analog processing via photochemistry in the absence of radiation chemistry.

\section{Experimental}

The ultrahigh vacuum chamber used for these experiments has been described in detail

previously. ${ }^{22}$ The chamber is evacuated by a turbomolecular pump, a rotary vane mechanical pump, an ion pump, and a titanium sublimation pump to maintain pressures of $\sim 1 \times 10^{-9}$ Torr, 
as monitored by a nude ion gauge. A Ta(110) single crystal is mounted on a precision sample manipulator capable of $\mathrm{x}, \mathrm{y}$, and $\mathrm{z}$ translations, as well as polar rotation via a differentiallypumped rotary feedthrough. For cleaning, the crystal is heated briefly via radiative heating and electron bombardment to approximately $2200 \mathrm{~K}$ which exceeds the desorption temperatures of oxygen and sulfur. The crystal is cooled to $\sim 90 \mathrm{~K}$ with liquid nitrogen.

Gaseous deuterated ammonia (99 atom\% D, Cambridge Isotope Laboratories) is dosed via a precision leak valve onto the cleaned and cooled crystal to form thin films of crystalline ammonia ices. The number of monolayers (ML) deposited is quantified by the corresponding pressure drop in the gas handling lines as measured by a capacitance manometer capable of measuring pressure in torr to a precision of one part in 10,000 . One monolayer is defined as the maximum exposure of ammonia that does not yield a multilayer peak.

After deposition of ammonia, the crystal is turned to face a recently commercialized laser-driven low-energy broadband photon source (Energetiq EQ-1500 LDLS ${ }^{\mathrm{TM}}$ ) which emits photons of wavelengths $170-2400 \mathrm{~nm}$ with only small variations in spectral radiance with photon energy, as characterized by the manufacturer. In the photon energy range $6.0-7.4 \mathrm{eV}$ relevant to our study of ammonia, the incident flux is $6 \pm 1 \times 10^{15}$ photons $\mathrm{cm}^{-2} \mathrm{~s}^{-1}$, as measured by a movable FGAP71 photodiode (Thorlabs) positioned at the sample location. The deep-UV to near-IR output has a relatively flat spectrum with a brightness higher than that of traditional lamps such as deuterium lamps and Xe arc lamps, especially in the deep UV. The incident photon flux is stable, showing a temporal variation of less than $1 \%$.

For post-irradiation temperature-programmed desorption experiments, following photon irradiation, the crystal is turned to face a Hiden Ion Desorption Probe Series 500 quadrupole 
mass spectrometer and heated radiatively with a nearly constant heating rate of $\sim 7 \mathrm{~K} / \mathrm{s}$ to approximately $800 \mathrm{~K}$, causing desorption of photolysis products.

\section{Results \& Discussion}

We present novel data identifying hydrazine $\left(\mathrm{N}_{2} \mathrm{D}_{4}\right)$, diazene (diimide) $\left(\mathrm{N}_{2} \mathrm{D}_{2}\right)$, triazane $\left(\mathrm{N}_{3} \mathrm{D}_{5}\right)$, and one or more isomers of $\mathrm{N}_{3} \mathrm{D}_{3}$ as products of condensed ammonia irradiated with photons with energies less than $7.4 \mathrm{eV}$, below condensed ammonia's ionization threshold of $\sim 9 \mathrm{eV}$. In temperature-programmed desorption control (no photon irradiation) experiments involving thin films of deuterated ammonia $\left(\mathrm{ND}_{3}\right)$ grown on a $\mathrm{Ta}(110)$ crystal surface, a small peak appears in ion channels of $m / z 32\left(\mathrm{~N}_{2} \mathrm{D}_{2}{ }^{+}\right), m / z 36\left(\mathrm{~N}_{2} \mathrm{D}_{4}{ }^{+}\right), m / z 48\left(\mathrm{~N}_{3} \mathrm{D}_{3}{ }^{+}\right)$, and $m / z 52\left(\mathrm{~N}_{3} \mathrm{D}_{5}{ }^{+}\right)$at approximately $115 \mathrm{~K}$, the desorption temperature of ammonia (Figure 1); these peaks are attributed to ion-molecule gas-phase reactions of $\mathrm{ND}_{3}$ within the ionizer of the mass spectrometer.

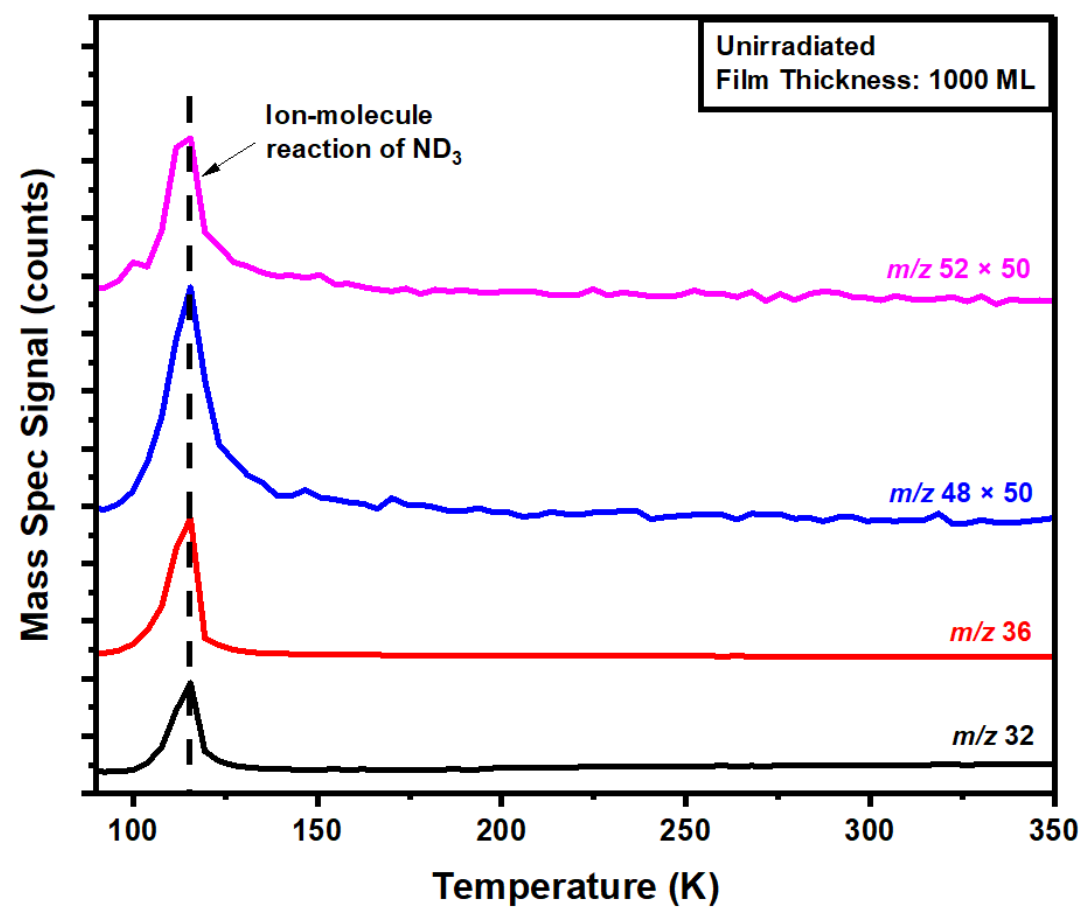

Figure 1 
Representative temperature-programmed desorption experiment performed in the absence of radiation, in which only unreacted ammonia is detected.

After irradiation with low-energy $(0.5-7.4 \mathrm{eV})$ photons, several photolysis products are detected during temperature-programmed desorption (Figure 2). Hydrazine $\left(\mathrm{N}_{2} \mathrm{D}_{4}\right)$ desorbs at approximately $155 \mathrm{~K}$ as shown by peaks in the $m / z 32\left(\mathrm{~N}_{2} \mathrm{D}_{2}{ }^{+}\right)$and $m / z 36\left(\mathrm{~N}_{2} \mathrm{D}_{4}{ }^{+}\right)$ion channels. The peak at approximately $185 \mathrm{~K}$ in the $m / z 32\left(\mathrm{~N}_{2} \mathrm{D}_{2}{ }^{+}\right)$ion channel is attributed to diazene (diimide) $\left(\mathrm{N}_{2} \mathrm{D}_{2}\right)$ desorption. Triazane $\left(\mathrm{N}_{3} \mathrm{D}_{5}\right)$ desorption occurs at approximately $150 \mathrm{~K}$, as shown by peaks in the $m / z 52\left(\mathrm{~N}_{3} \mathrm{D}_{5}{ }^{+}\right)$and $m / z 48\left(\mathrm{~N}_{3} \mathrm{D}_{3}{ }^{+}\right)$ion channels. The peaks at approximately $190 \mathrm{~K}, 230 \mathrm{~K}$, and $260 \mathrm{~K}$ in the $m / z 48\left(\mathrm{~N}_{3} \mathrm{D}_{3}{ }^{+}\right)$ion channel are attributed to the desorption of one or more isomers of $\mathrm{N}_{3} \mathrm{D}_{3}$. The multiple desorption temperatures for $\mathrm{N}_{3} \mathrm{D}_{3}$ are likely due to multiple adsorption sites or multiple isomers of $\mathrm{N}_{3} \mathrm{D}_{3}$ or both. Isomers of $\mathrm{N}_{3} \mathrm{D}_{3}$ include trans-triazene, cis-triazene, cyclotriazane, triimide, and isotriazene. Remarkably, lowenergy $(<7.4 \mathrm{eV})$ photon irradiation of condensed ammonia leads to the formation of dimers (hydrazine and diazene (diimide)) and trimers (triazane), the beginning of oligomerization.

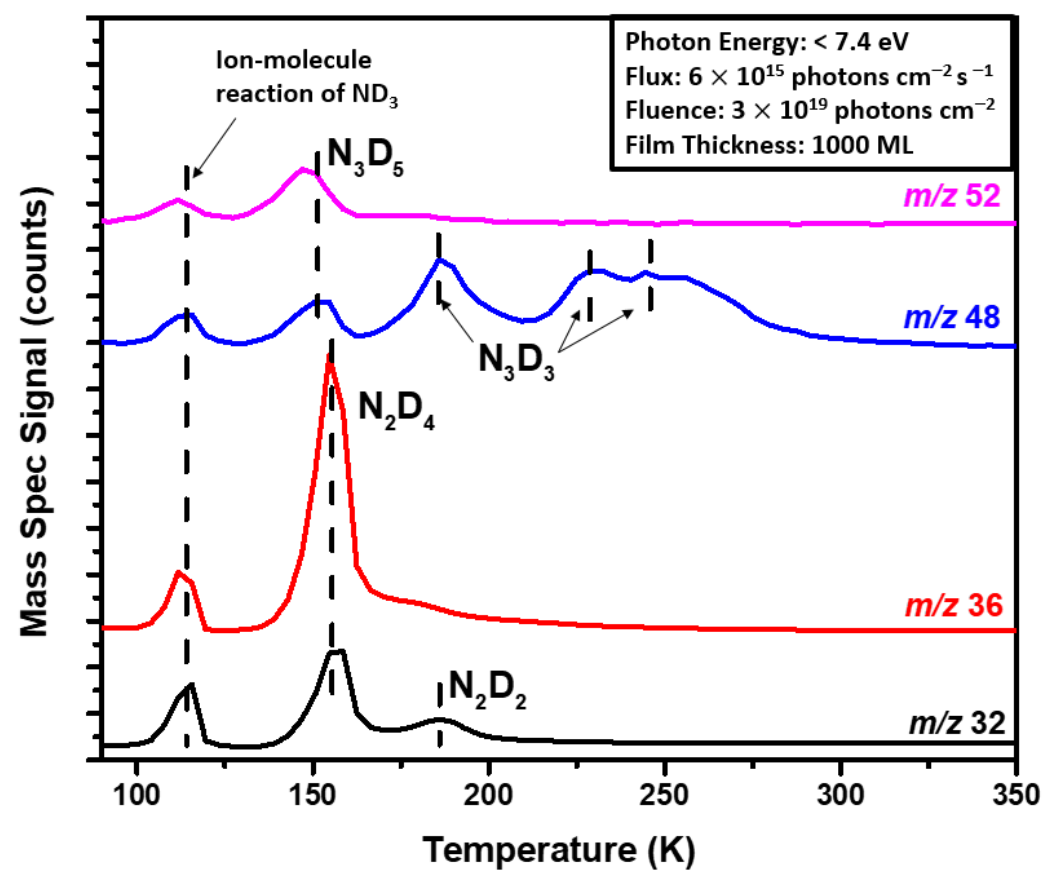

Figure 2 
Following irradiation of condensed $\mathrm{ND}_{3}$ with $<7.4 \mathrm{eV}$ photons with a fluence of $3 \times 10^{19}$ photons $\mathrm{cm}^{-2}$, hydrazine $(\mathrm{m} / \mathrm{z} 36,32)$, diazene (diimide) $(\mathrm{m} / \mathrm{z} 32)$, triazane $(\mathrm{m} / \mathrm{z} 52,48)$, and one or more isomers of $\mathrm{N}_{3} \mathrm{D}_{3}(\mathrm{~m} / \mathrm{z} 48)$ are detected during temperature-programmed desorption experiments.

Various post-irradiation studies utilizing high-energy $(\sim 550 \mathrm{MeV})$ heavy ions $\left({ }^{64} \mathrm{Ni}^{24+}\right.$ and $\left.{ }^{70} \mathrm{Zn}^{26+}\right)$, high-energy $(150 \mathrm{eV})$ photons, or high-energy $(0.5-5 \mathrm{keV})$ electrons have identified hydrazine, ${ }^{13,23-24}$ diazene (diimide), ${ }^{13,23-26}$ triazane, ${ }^{25}$ and one or more isomers of $\mathrm{N}_{3} \mathrm{H}_{3}{ }^{25,27}$ as radiation chemistry products of pure condensed ammonia. By using photoionization-driven reflectron time-of-flight mass spectroscopy during temperatureprogrammed desorption experiments, the $\mathrm{N}_{3} \mathrm{H}_{3}$ ammonia radiolysis products were identified as triazene $\left(\mathrm{H}_{2} \mathrm{NNNH}\right)$ and possibly triimide $(\mathrm{HNHNNH}) .{ }^{27}$ Because radiolysis and photolysis products of ammonia appear to be the same, electron/photon-induced electronic excitation (rather than ionization or dissociative electron attachment) likely play a central role in the energetic processing of cosmic ices. Experiments are currently underway in our laboratory to compare yields and branching ratios to identify astrochemically-relevant differences between radiation chemistry and photochemistry of condensed ammonia.

To confirm that photochemistry is the only process involved in product formation, the possible ejection of electrons from the metal crystal surface via the photoelectric effect was investigated. The mean free path $(\lambda)$ of a $7-\mathrm{eV}$ photon is calculated to be $0.2 \mu \mathrm{m}$ :

$$
\lambda=\frac{1}{n \sigma}
$$

In Equation (1), $n$ is the number of molecules per $\mathrm{cm}^{3}$ and $\sigma$ is the photon absorption cross section which is $2 \times 10^{-18} \mathrm{~cm}^{2}$ for condensed ammonia. ${ }^{28}$

The film thickness of a $300 \mathrm{ML}$ thin film is estimated to be approximately $0.1 \mu \mathrm{m}$, suggesting that photons could indeed penetrate the film and interact with the crystal metal surface below. Because the maximum photon energy used in these experiments is $7.4 \mathrm{eV}$ and 
the photoelectric threshold of $\mathrm{Ta}(110)$ is $4.5 \mathrm{eV}$, the photoejected electron's maximum kinetic energy is:

$$
K_{\max }=h v-\phi=7.4 \mathrm{eV}-4.5 \mathrm{eV}=2.9 \mathrm{eV}
$$

Previous studies of dissociative electron attachment processes in condensed ammonia show dissociative electron attachment resonances at $\sim 10 \mathrm{eV}$ and $\sim 6 \mathrm{eV}$, well above the maximum kinetic energy of the photo-ejected electrons calculated in Equation (2). ${ }^{29}$ In addition, electroninduced electronic excitation leading to the dissociation of ammonia is not feasible at incident electron energies below $4 \mathrm{eV}$ (see below). Thus, we conclude that in the experiments described herein, only photons are responsible for the formation of dimers and trimers from condensed ammonia.

Only photons with energies $6.0-7.4 \mathrm{eV}$ are likely effective in the formation of the detected ammonia photolysis products because the absorption spectrum ${ }^{28,30}$ of condensed ammonia displays a lower limit of $6.0 \mathrm{eV}$ and the photon source used in our experiments has an upper limit of $7.4 \mathrm{eV}$. Moreover, it is unlikely that two-photon absorbance plays a role in these experiments because of the relatively low flux $\left(\sim 6 \times 10^{15}\right.$ photons $\left.\mathrm{cm}^{-2} \mathrm{~s}^{-1}\right)$ of our UV lamp as compared to the laser sources such as $\operatorname{ArF}$ excimer lasers $\left(\sim 10^{24}\right.$ photons $\left.\mathrm{cm}^{-2} \mathrm{~s}^{-1}\right)$ typically used to induce two-photon absorption. ${ }^{31}$

Irradiation of condensed ammonia with $<7.4 \mathrm{eV}$ photons likely produces both amidogen $\left(\mathrm{NH}_{2}\right)$ and imine (imidogen) $(\mathrm{NH})$ radicals. The production of ground-state amidogen $\left(\mathrm{NH}_{2}\right)$ radicals (Equation 3) has a threshold of $4.6 \mathrm{eV}$ for the gas-phase spin-allowed photon-induced excitation process. ${ }^{32}$ 


$$
\mathrm{NH}_{3}+h v \rightarrow \mathrm{NH}_{2}\left(\tilde{\mathrm{X}}^{2} \mathrm{~B}_{1}\right)+\mathrm{H}
$$

The photon-induced gas-phase formation of the $\mathrm{NH}$ radical ground $\mathrm{X}^{3} \Sigma^{-}$state from ammonia (Equation 4) has a threshold energy of $4.1 \mathrm{eV}$ but is nominally spin-forbidden. ${ }^{24}$

$$
\mathrm{NH}_{3}+h v \rightarrow \mathrm{NH}\left(\mathrm{X}^{3} \Sigma^{-}\right)+\mathrm{H}_{2}
$$

While photon-induced singlet-to-triplet transitions are nominally forbidden in the gas phase, these spin-forbidden photon-induced transitions may be allowed in the condensed phase. ${ }^{33}$ Even though the threshold energies to produce such radicals are consistently blue-shifted by $\sim 1.2 \mathrm{eV}$ in the condensed phase as compared to the gas phase, ${ }^{15,30}$ the formation of ground-state $\mathrm{NH}_{2}$ and $\mathrm{NH}$ radicals via electronic excitation of $\mathrm{NH}_{3}$ must occur because the UV source has a nearconstant flux at photon energies below $7.4 \mathrm{eV}$. The formation of excited amidogen $\left(\mathrm{NH}_{2}\right)$ and excited imine $(\mathrm{NH})$ radicals is also possible given the gas-phase threshold energies of 5.9 and $5.7 \mathrm{eV}$ for the photon-induced decomposition of ammonia to form $\mathrm{NH}_{2}\left(\tilde{\mathrm{A}}^{2} \mathrm{~A}_{1}\right)$ and $\mathrm{NH}\left(\mathrm{a}^{1} \Delta\right)$, respectively. Because the activation energy for radical diffusion is relatively low $(\sim 50 \%$ of desorption energy), facile diffusion of even relatively large radicals is possible at temperatures as low as $30 \mathrm{~K} .{ }^{34}$ Diffusion of amidogen $\left(\mathrm{NH}_{2}\right)$ and imidogen $(\mathrm{NH})$ radicals in the irradiated ammonia ices is likely given the relatively high ice temperatures $(\sim 90 \mathrm{~K})$ used in this study. Thus, the products detected during our temperature-programmed desorption experiments are likely formed during irradiation and not during the subsequent thermal processing. Therefore, we attribute the formation of hydrazine and diazene (diimide) to the barrier-less self-reaction of ground or excited state amidogen $\left(\mathrm{NH}_{2}\right)$ radicals (Equation 5) and imine (imidogen) $(\mathrm{NH})$ radicals (Equation 6), respectively. 


$$
\begin{aligned}
& \mathrm{NH}_{2}+\mathrm{NH}_{2} \rightarrow \mathrm{N}_{2} \mathrm{H}_{4} \\
& \mathrm{NH}+\mathrm{NH} \rightarrow \mathrm{N}_{2} \mathrm{H}_{2}
\end{aligned}
$$

Based on a radiolysis study of isotopically labeled condensed ammonia, the formation of $\mathrm{N}_{3} \mathrm{H}_{3}$ was attributed to reactions between diazene (diimide) $\left(\mathrm{N}_{2} \mathrm{H}_{2}\right)$ and amidogen $\left(\mathrm{NH}_{2}\right)$ or imine (imidogen) $(\mathrm{NH})$ or both. ${ }^{27}$

Product yields increase monotonically when (1) the photon fluence is increased from 2 $\times 10^{18}$ photons $\mathrm{cm}^{-2}$ to $3 \times 10^{19}$ photons $\mathrm{cm}^{-2}$ (Figure 3 ) at constant film thickness and (2) the film thickness is increased from $25 \mathrm{ML}$ to $1000 \mathrm{ML}$ at constant fluence (Figure 4).

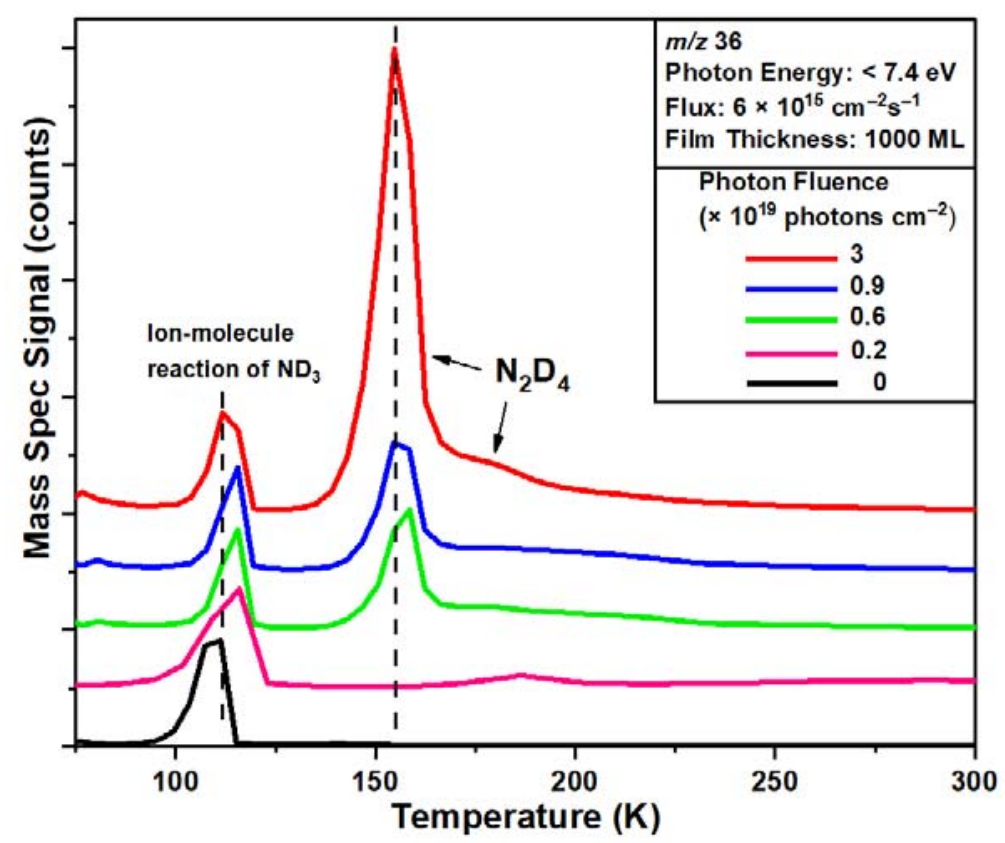

Figure 3

Hydrazine yields increase monotonically as photon fluence is increased from $2 \times 10^{18}$ photons $\mathrm{cm}^{-2}$ to $3 \times 10^{19}$ photons $\mathrm{cm}^{-2}$ by holding photon energy constant and increasing irradiation time. The number of monolayers is held constant at $1000 \mathrm{ML}$. 


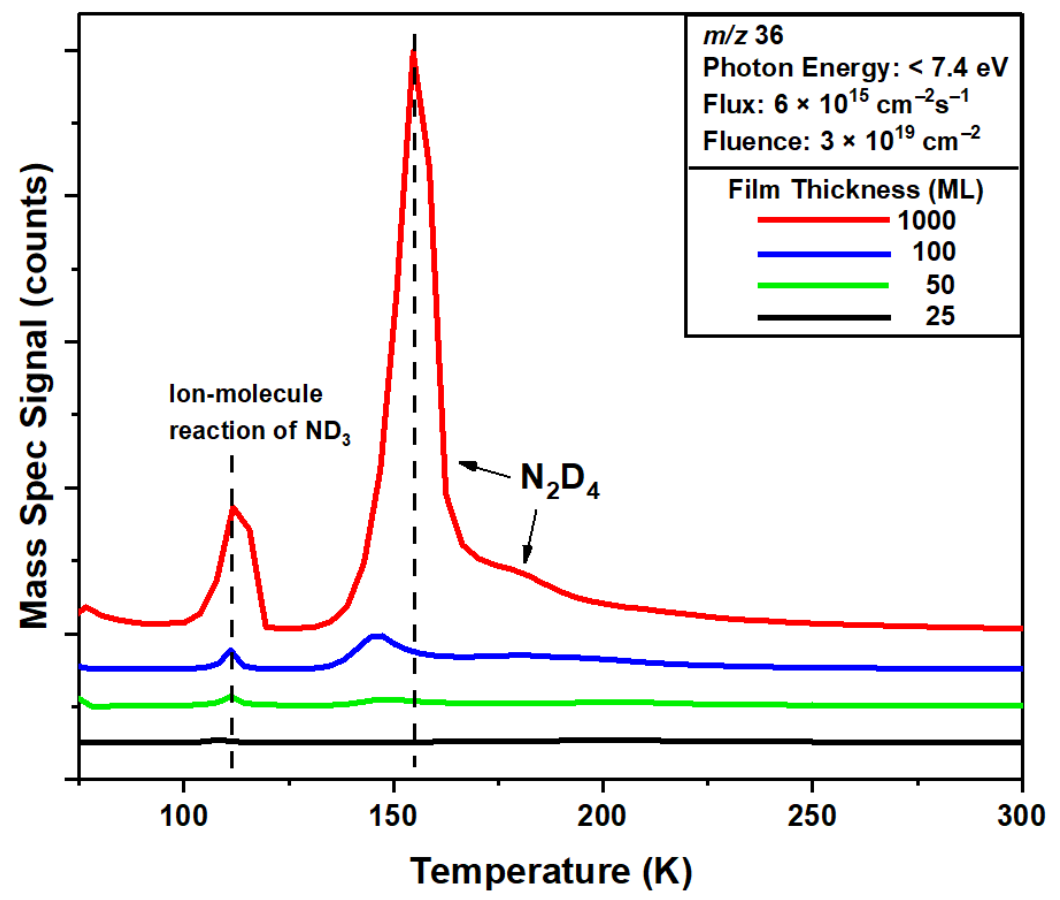

Figure 4

Hydrazine yields increase monotonically as film thickness is increased from 25 to 1000 monolayers. Photon fluence is held constant at $3 \times 10^{19}$ photons $\mathrm{cm}^{-2}$.

Future studies will involve the collection of additional quantitative data amenable to mechanistic interpretations. Such studies will also employ a bandpass filter to constrain photon energies further.

\section{Conclusions}

Results of our post-irradiation temperature-programmed desorption studies demonstrate that low-energy $(<7.4 \mathrm{eV})$ photon irradiation of condensed ammonia leads to dimerization and trimerization, the beginning of oligomerization. Although photochemistry is cited as a dominant mechanism for the synthesis of prebiotic molecules in interstellar ices, ${ }^{35}$ to the best of our knowledge, this study is one of the first experimental astrochemistry studies ${ }^{14,36}$ that has found unambiguous evidence for chemical synthesis induced by photons in the absence of ionization. 


\section{Conflicts of Interest}

There are no conflicts to declare.

\section{Acknowledgments}

This work was supported by grants from the National Science Foundation (NSF grant number

CHE-1465161), Wellesley College (Faculty awards and Brachman Hoffman small grants), and

Clark University (Sherman Fairchild Summer Scholars Program and the Physics Department).

\section{References}

1. Wardle, B. Principles and Applications of Photochemistry; Wiley; Chichester, U.K., 2009.

2. George, C.; Ammann, M.; D'Anna, B.; Donaldson, D. J.; Niskorodov, S. A. Heterogeneous photochemistry in the atmosphere, Chem. Rev., 2015, 115, 4218-4258.

3. Woods, R. J. Basics of Radiation Chemistry. Environmental Applications of Ionizing

Radiation, William J. Cooper, K. E. O. S., Ed., Wiley, 1998, pp 752.

4. Obreshkove, V. The photic reactions of tadpoles in relation to the Bunsen-Roscoe law, $J$. Exp. Zool,. 1921, 34, 234-279.

5. Shibaguchi, T.; Onuki, H.; Onuka, R. Electronic structures of water and ice, J. Phys. Soc. Jpn., 1977, (42), 152-158.

6. Sieger, M. T.; Simpson, W. C.; Orlando, T. M. Electron-stimulated desorption of D+ from D2O ice: Surface structure and electronic excitations, Phys. Rev. B., 1997, 56 (8), 49254937.

7. Kahn, A. Fermi level, work function and vacuum level, Mater. Horiz., 2016, 3 (1), 7-10. 
8. Lias, S. G. Ionization energy evaluation, NIST Standard Reference Database Number 69, P. J. Linstrom, W. G. M., Ed., National Institute of Standards and Technology, Gaithersburg.

9. Yu, K. Y.; McMenamin, J. C.; Spicer, W. E. UPS measurements of molecular energy level of condensed gases, Surf. Sci, 1975, 50, 149-156.

10. Cruz-Diaz, G. A.; Muñoz-Caro, G. M.; Jimenez-Escobar, A. Photodesorption and product formation in UV-irradiated $\mathrm{N} 2$ and $\mathrm{NH} 3$ ices under ultra-high-vacuum conditions, EAS Publications, 2012, 58 (EAS Publications Series), 333-336.

11. Martín-Doménech, R. Cruz-Díaz, G. A.; Muñoz-Caro, G. M. UV photoprocessing of NH3 ice: photon-induced desorption mechanisms, Mon. Not. R. Astron. Soc., 2018, 473 (2), $2575-2582$.

12. Gerakines, P. A.; Schutte, W. A.; Ehrenfreund, P. Ultraviolet processing of interstellar ice analogs .1. Pure ices, Astron. Astrophys., 1996, 312 (1), 289-305.

13. Parent, P.; Bournel, F.; Lasne, J.; Lacombe, S.; Strazzulla, G.; Gardonio, S.; Lizzit, S.; Kappler, J. P.; Joly, L.; Laffon, C.; Carniato, S. The irradiation of ammonia ice studied by near edge x-ray absorption spectroscopy, J. Chem. Phys., 2009, 131 (15).

14. Nishi, N. Shinohara, H.; Okuyama, T. Photodetachment, photodissociation, and photochemistry of surface molecules of icy solids containing NH3 and pure $\mathrm{H} 2 \mathrm{O}$ ices, $J$. Chem. Phys., 1984, 80 (8), 3898-3910.

15. Loeffler, M. J.; Baragiola, R. A. Photolysis of solid NH3 and NH3-H2O mixtures at 193 nm, J Chem. Phys., 2010, 133 (21).

16. Prasad, S. S.; Tarafdar, S. P. UV radiation field inside dense clouds - its possible existence and chemical implications, Ap. J., 1983, 267, 603-609. 
17. Herbst, E. The synthesis of large interstellar molecules, Int. Rev. Phys. Chem., 2017, 36 (2), 287-331.

18. Öberg, K. I.; Boogert, A. C. A.; Klaus, M. P.; Saskia van den, B.; Ewine, B. v. D.; Sandrine, B.; Geoffrey, A. B.; Neal, J. E., II. The Spitzer ice legacy: Ice evolution from cores to protostars, Ap. J., 2011, 740 (2), 109.

19. Greenberg, J. M.;Vandebult, C.; Allamandola, L. J. Ices in space, J. Phys. Chem., 1983, 87 (21), 4243-4260.

20. Altwegg, K.; Balsiger, H.; Bar-Nun, A.; Berthelier, J. J.; Bieler, A.; Bochsler, P.; Briois, C.; Calmonte, U.; Combi, M. R.; Cottin, H. et al. Prebiotic chemicals-amino acid and phosphorus-in the coma of comet 67P/Churyumov-Gerasimenko, Sci. Adv., 2016, 2 (5).

21. Boyer, M. C.; Rivas, N.; Tran, A. A.; Verish C. A.; Arumainayagam, C. R. The role of lowenergy $(<20 \mathrm{eV})$ electrons in astrochemistry, Surf. Sci., 2016, 652, 26-32.

22. Harris, T. D.; Lee, D. H.; Blumberg, M. Q.; Arumainayagam, C. R. Electron-induced reactions in methanol ultrathin films studied by temperature-programmed desorption - a useful method to study radiation chemistry, J. Phys. Chem., 1995, 99 (23), 9530-9535.

23. Bordalo, V.; da Silveira, E. F.; Lv, X. Y.; Domaracka, A.; Rothard, H.; Duarte, E. S.; Boduch, P. Chemical processing of pure ammonia and ammonia-water ices induced by heavy ions, Ap. J., 2013, 774 (2).

24. Zheng, W. J.; Jewitt, D.; Osamura, Y.; Kaiser, R. I. Formation of nitrogen and hydrogenbearing molecules in solid ammonia and implications for solar system and interstellar ices, Ap. J., 2008, 674 (2), 1242-1250. 
25. Forstel, M.; Maksyutenko, P.; Jones, B. M.; Sun, B. J.; Chen, S. H.; Chang, A. H.; Kaiser, R. I. Detection of the elusive triazane molecule (N3H5) in the gas phase, Chem. Phys. Chem., 2015, 16 (15), 3139-42.

26. Barberio, M.; Barone, P.; Vasta, R.; Manico, G.; Xu, F. Formation of molecular nitrogen and diazene by electron irradiation of solid ammonia, Thin Solid Films, 2012, 520 (16), $5479-5481$.

27. Förstel, M.; Tsegaw, Y. A.; Maksunyutenko, P.; Mebel, A. M.; Sander, W.; Kaiser, R. I. On the formation of $\mathrm{N} 3 \mathrm{H} 3$ isomers in irradiated ammonia-bearing ices: Triazene $(\mathrm{H} 2 \mathrm{NNNH})$ or Triimide (HNHNNH), Chem. Phys. Chem., 2016, 17, 2726-2735.

28. Mason, N. J.; Dawes, A.; Holtom, P. D.; Mukerji, R. J.; Davis, M. P.; Sivaraman, B.; Kaiser, R. I.; Hoffman, S. V.; Shaw, D. A. VUV spectroscopy and photo-processing of astrochemical ices: an experimental study, Farad. Discuss., 2006, (133), 311-329.

29. Tronc, M.; Azria, R.; LeCoat, Y.; Illenberger, E. Threefold differential electron-stimulated desorption yields of D- anions from multilayer films of D2O and ND3 condensed on platinum, J. Phys. Chem., 1996, 100 (35), 14745-14750.

30. Dawes, A.; Mukerji, R. J.; Davis, M. P.; Holtom, P. D.; Webb, S. M.; Sivaraman, B.; Hoffmann, S. V.; Shaw, D. A.; Mason, N. J. Morphological study into the temperature dependence of solid ammonia under astrochemical conditions using vacuum ultraviolet and Fourier-transform infrared spectroscopy, J. Chem. Phys,. 2007, 126 (24), 244711.

31. Stuhl, F.; Haak, H. K. ArF excimer laser photolysis of ammonia. Formation of NH and ND in the A3Pi state, J. Phys. Chem., 1984, 88, 2201-2204.

32. Leach, S.; Jochims, H. W.; Baumgartel, H. VUV Photodissociation of ammonia: a dispersed fluorescence excitation spectral study, Phys. Chem. Chem. Phys., 2005, 7 (5), 900-911. 
33. Bondybey, V. E.; Smith, A. M., Agreiter, J. New developments in matrix isolation spectroscopy, Chem. Rev., 1996, 96 (6), 2113-2134.

34. Garrod, R. T.; Herbst. E. Formation of methyl formate and other organic species in the warm-up phase of hot molecular cores, Astron. Astrophys., 2006, 457, 927-936.

35. Öberg, K. I. Photochemistry and astrochemistry: Photochemical pathways to interstellar complex organic molecules, Chem. Rev., 2016, 116 (17), 9631-9663.

36. de Marcellus, P.; Meinert, C.; Nuevo, M.; Filippi, J. J.; Danger, G.; Deboffle, D.; Nahon, L.; d'Hendecourt, L. L. S.; Meierhenrich, U. J. Non-racemic amino acid production by ultraviolet irradiation of achiral interstellar ice analogs with circularly polarized light, Astrophys. J. Lett. 2011, 727 (2), 6. 